\title{
Design and Development of Door Access System using Radio Frequency Identification
}

\author{
Naseem Rao \\ Assistant Professor, CSE Department, Hamdard University, Delhi, India
}

\begin{abstract}
In this paper, RFID based Door access control using Arduino is based upon security access and control system using RFID and Arduino. The embedded chips in RFID use radio signals to capture and read information on the object. Barcodes labels have been in the industry for over more than 30 years but over a past decade, new technologies like Radio Frequency Identification (RFID) have diminished the luster of barcodes. RFID technology is significant and consistent means to identify the material. Arduino helps to design the circuit and makes programming a lot easier to understand.
\end{abstract}

Keywords: RFID, Arduino; Health monitoring; LED

\section{INTRODUCTION}

Now that technology is so advanced, unique access control systems have turned out important to prevail security threats to various organisations. Access control system restricts entrance to a property, a building, or a room to authorized persons [1]. In the field of information and privacy security, door access control systems are playing major vital roles to safeguard organizations [2]. This is a time where everything is associated with the system, where anybody can get hold of data from anyplace around the globe. Therefore, hacking of one's information is a major issue. Because of these dangers, it is imperative to have some sort of personal Identification (ID) to get to one's own particular information. Security access system is very convenient to use at home, office and commercial buildings [3]. All these years, various systems are introduced to track the individual's movement. Among standard individual ID strategies, password and ID card methods are the most observed methods. However, it is not very difficult to hack secret password now and recognizable ID cards may get lost, hence making these techniques very questionable.

Radio Frequency Identification (RFID) is a revolutionary innovation that can be utilized to evolve the entrance control system [4-5]. It provides a automation in various processes ranging from industrial sectors to home control.

RFID technology will help us to develop a door access control system which can allow the entry of authorized personnel in the restricted zones [6]. Moreover this technology is employed popularly in control access systems which has wide range of applications in areas such as personnel identification, consumer goods tracking and so on.[7]

\section{PROPOSED ARCHITECTURE}

RFID based security system using Arduino has a RFID reader attached to it. RFID reader reads the unique alphanumeric code of RFID tags and sends it to Arduino. Then Arduino detects whether RFID card is valid or invalid. If the card is invalid then system turns on the buzzer. However, if the RFID card shown by the user is valid then the servo motor is turned on and door open.

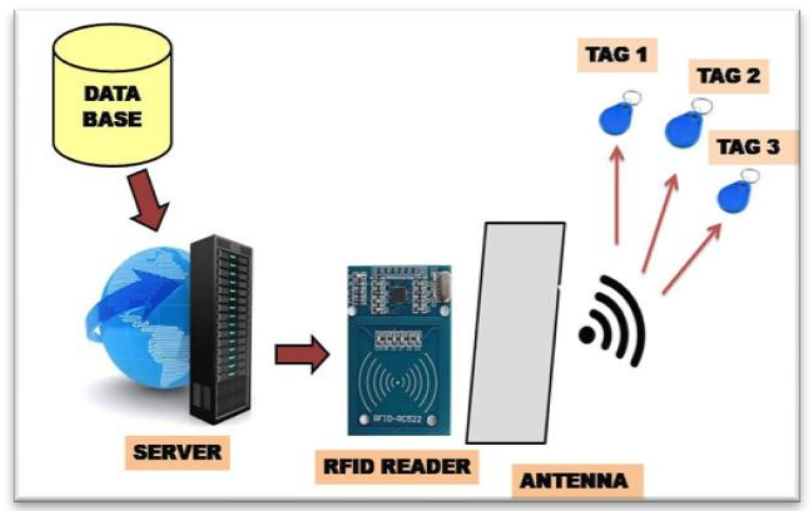

Fig 1: RFID Control access system 
When we switch on the power supply, the default white LED lights up, which shows that the automated system is activated. Every employee in the office has an ID card with specific details on it which can be tracked by the RFID reader whenever it is placed at specific range. The RFID card tag of each employee is stored in the main system. Each time when an employee touches tag close to the RFID reader, the antenna at the reader send the radio waves and read the data of the RFID card. All these actions are displayed on the system in the main office.

Whenever a person with specific ID tag tries to get into the restricted area, he/she has to touch the card. If the details of that unique card are already stored in the system, then the green Led lights up and buzzer rings up and the door opens automatically. If the details on the card does not match with the record stored in the system, then the entry of that person is denied, the door does not opens and the red LED lights up with the buzzer. The door will automatically open and close when the right RFID tag is placed within the range of RFID reader.

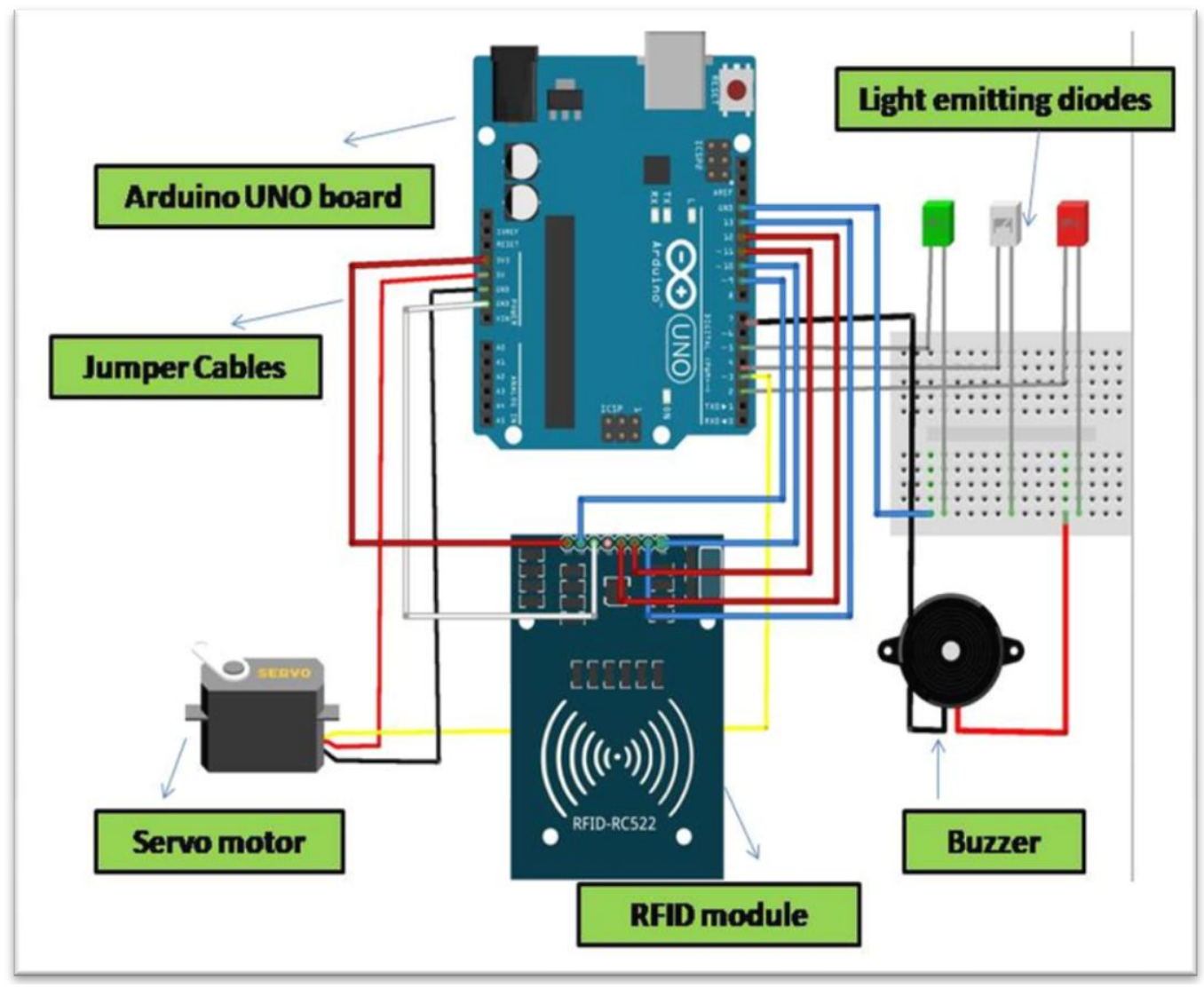

Fig 2: Circuit diagram of developed model

The development of our project RFID based Door access control using Arduino is mainly used for interfacing RFID reader with Arduino. The circuit comprise of three separate parts, namely reader, controller and door lock. In our project we use RFID system to open door. For instance only the person with right information on his card is allowed to enter. RC522 RFID has been used .It interface the RC522 with Arduino as follows:

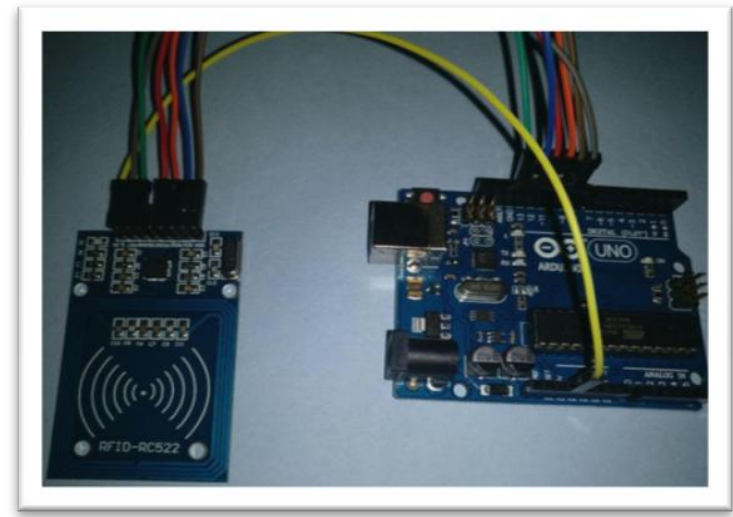

Fig 3: RFID interfaced with Arduino 
Vol. 8, Issue 4, April 2019

\section{CONCLUSION}

RFID based security and access control system is a fast and highly secured system as compared to any other biometric systems. It provides contact less communication and works without the line of sight.With the help of Arduino, the system are easily accessible and works indefinitely. Users can change the functions in the Arduino code. RFID control system reduces human effort and error. And with the help of this multiple RFID tags can be read at a time which leads to high efficiency of RFID system. Radio frequency identification (RFID) is a remote innovation that can be utilized to evolve the entrance control system. This technology provides a revolutionary automation in various processes ranging from industrial sectors to home control.

\section{REFERENCES}

[1]. V. Subramanian, P. C. Chang, D. Huang, J. B. Lee, S. E. Molesa, D. R. Redinger, and S. K.Volkman, "Printed organic transistors forultralowcost RFID applications", IEEE Transactions on Components And Packaging Technologies, 2005

[2]. A. Juels RFID security and privacy: A research survey IEEE Journal on chosen areas in Computing, 24(2):381-394, February 2006.

[3]. M. R. Rieback, B. Crispo, \& A. S. Tanenbaum, "The Evolution of RFID Security"; Pervasive Computing, IEEE Volume 5, Iss1, Jan-Mar. 2006

[4]. N. Ahmad, S. Butler, and U. Ramachandran, "GuardianAngel: An RFID based indoor guidance and monitoring system,” 2010 , pp. 546-551.

[5]. K. S. Huang and S. M. Tang, "RFID applications strategy and deployment in bike renting system," in Proc. ICACT 2008 , pp. 660-663.

[6]. S. Lahiri, RFID sourcebook, IBM Press, Westford, Massachusetts, 2006.

[7]. F. Lourenco and C. Almeida, "RFID based monitoring and access control system," in Proc. INFORUM, 2009

[8]. R. Weinstein, "RFID: A technical overview and its application to the enterprise," IT Professional, vol. 7, no. 3, May-June 2005, pp. 27-33.

[9]. X. L. Meng, Z. W. Song, and X. Y. Li, "RFID-Based security authentication system based on a novel face-recognition structure," in Proc. WASE International Conference on Information Engineering, 2010, pp. 97-100.

[10]. D. L. Wu, Wing W. Y. NG, Patrick P. K. Chan, H. L. Ding, B. Z. Jing, and D. S. Yeung, "Access control by RFID and face recognition based on neural network," in Proc. International Conference on Machine Learning and Cybernatics, July 11-14, 2010, pp. 675-680. 